\title{
Foraging behavior as a determinant of asymmetric competitive interaction between two ant species in a tropical agroecosystem
}

Received: 24 April 1993 / Accepted: 15 February 1994

\begin{abstract}
This work is concerned with elucidating competitive interactions between two neotropical ants, Solenopsis geminata and Pheidole radoszkowskii, focusing on their foraging behavior. When released from competition from $P$. radoszkowskii, $S$. geminata increased its foraging activity. On the other hand, when released from competition from $S$. geminata, $P$. radoszkowskii did not respond, demonstrating asymmetric competition between the two species. Foraging experiments showed that $P$. radoszkowskii is more efficient at finding food resources, whereas $S$. geminata is better at defending the resources once they are encountered. These differences in foraging behavior appear to permit the coexistence of these two species. The practical implications of the results for the management of ant communities in tropical agroecosystems is discussed with respect to the potential use of ants as natural enemies.
\end{abstract}

Key words Solenopsis geminata Pheidole radoszkowskii . Formicidae - Competition release Coffee plantations

\section{Introduction}

Questions related to what constitutes a resource and by what mechanisms organisms divide or share resources have been central to ecology. Numerous experiments have addressed the question of what is partitioned and how it is partitioned. Habitat, food type and time have been the central themes of these experimental studies (Levins et al. 1973; Swain 1977; Hölldobler 1981), with an occasional reference to particular patterns of foraging behavior and morphology as determinants of resource partitioning (Hansen 1978; Brown et al. 1979; Vepsäläi-

I. Perfecto

School of Natural Resources and Environment,

University of Michigan,

Ann Arbor,

MI 48109-1115, USA nen and Pisarski 1982; Schoener 1986; Sovalainen and Vepsäläinen 1989).

Ants are ideal organisms in which to study the interplay of competitive interactions and foraging behavior. When tested, ants frequently show interspecific competition in field experiments, and often the competition is of the interference type in which species affect one another directly, frequently by fighting (Schoener 1986). But these interactions are, in turn, influenced by the specific foraging behavior (i.g., timing, distribution in space, number of recruits, mode of encountering resources) of the species involved.

Many agroecosystems in Mesoamerica are dominated by two species of ground-foraging generalist ants, Solenopsis geminata Fabricus and Pheidole radoszkowskii Mayr. Agroecosystems ranging from corn in the lowland Pacific plains of Nicaragua (Perfecto 1990, 1991a, 1991b, Perfecto and Sediles 1992) to the mid-elevation coffee plantations in Mexico and Central America (Benítez and Perfecto, 1990; Nestel and Dickschen 1990), contain either one or both of these species in abundance. Frequently, the two species appear to dominate the ground foraging generalist ant community (Benítez and Perfecto 1990; Sediles 1990; Perfecto and Sediles 1992), while in a highly disturbed site, $S$. geminata alone is the dominant species (Nestel and Dickschen 1990; Perfecto 1991b). Although $S$. geminata is aggressive, it does coexist with $P$. radoszkowskil, and sometimes appears to succumb to competition from $P$. radoszkowskii (Perfecto 1991b). This led me to the hypothesis that there is an asymmetry in the competitive relationship between these two species, with $P$. radoszkowskii being the competitive dominator and $S$. geminata occupying zones not occupiable by $P$. radoszkowskii.

If this view is true, certain predictions naturally follow for a competition release experiment. That is, the response to competitive release (the reciprocal elimination of each species from an area of co-occupation) ought to be asymmetrical, with S. geminata colonizing areas in which $P$. radoszkowskii has been eliminated (since the latter had been competitively suppressing the former), 
but $P$. radoszkowskii failing to recolonize areas in which $S$. geminata has been eliminated (because the presence of the latter is due to the unsuitability of the local habitat for the former).

The work reported here (1) describes the distribution of these two species in one field setting, (2) tests the hypothesis of asymmetric competition between the two species, and (3) explores differences in foraging behavior as a possible mechanism for competition and coexistence between the two species.

\section{Natural history of the system}

Most ground-foraging ants in tropical ecosystems are generalists and omnivorous (Carroll and Jansen 1973; Levings 1983). Their main food resources consist of bits of organic debris falling to the ground from the vegetation, as well as small sedentary or slow moving organisms such as insect eggs, larvae, pupae, and some slow moving adult arthropods (Risch 1981; Perfecto 1990, 1991a; Perfecto and Sediles 1992). Some species, including S. geminata, harvest seeds as well (Wilson 1978; Carroll and Risch 1984).

There is clearly a range in the size of available resources. The large resources, such as large cockroaches and other large arthropods or small vertebrates, are swarmed over by species that recruit, and it would appear obvious that the species with the most aggressive swarm is likely to outcompete the other species on these large resources. The dynamics of small resources are different. An individual ant, or a small group of ants, may take the entire resource directly to the nest. Thus the critical factor for small resources is not the species' ability to aggressively defend them, but rather how rapidly the resources are encountered, or the foraging efficiency.

A third resource that appears to be quite important to many ground foraging ants is honeydew from homopterans (Way 19963), especially those homopterans that feed on the roots of grasses. In coffee monocultures in Mesoamerica, $S$. geminata nests have been observed in the root mass of grasses. In those situations, aphids can reach extremely high numbers (personal observation). Several species of Pheidole and Brachymyrmex have also been observed to tend these same homopterans on the same grasses. It appears that homopterans act much as a large resource, mainly available to those ants able to aggressively defend them.

The coffee agroecosystem in Mesoamerica is currently undergoing a dramatic transformation that has had a notable effect on the community structure of the groundforaging generalist ant community (Nestel and Dickschen 1990; Perfecto and Vandermeer, in press). In particular, a community consisting of 10-12 species is reduced to one consisting of 2-6 species, as the traditional agroforestry coffee system is replaced with coffee monocultures. This study took place in one of these impoverished communities in which the two dominant species were $S$. geminata and $P$. radoszkowskii.

\section{Methods and materials}

All observations and experiments were conducted in experimental coffee plantations within the Center for Coffee Research (CICAFE) in Heredia Province, Costa Rica ( $10^{\circ} 09^{\prime} \mathrm{N}, 84^{\circ} 08^{\prime} \mathrm{W}$ ) between June and August 1991 and 1992, and in March 1993. The Center is at an elevation of $1180 \mathrm{~m}$, with a mean annual temperature of $19^{\circ} \mathrm{C}$, and a mean annual precipitation of $2800 \mathrm{~mm}$.

Distribution and foraging ranges of the two species

Three $6 \times 16 \mathrm{~m}$ plots were established within a coffee plantation where coffee was growing at a distance of $1.3 \mathrm{~m}$ between rows and $0.8 \mathrm{~m}$ between plants within rows. Plots were separated by at least $5 \mathrm{~m}$ from each other. To determine foraging ranges and nest distribution of each of the two species, tuna fish baits (about $1 \times 1 \times$ $0.5 \mathrm{~cm}^{3}$ ) were placed on the ground next to every second coffee plant, thus creating a $1.3^{\prime} 1.6 \mathrm{~m}^{2}$ grid. Fish baits are very effective in attracting both species of interest (Saks and Carroll 1980; Risch and Carroll 1982a, b; Nestel and Dickschen 1990; Perfecto 1990; Perfecto and Sediles 1992). The baits were checked 20 min after setting to allow sufficient time for ants to find them and establish a recruitment trail. All ant baiting was conducted between 07:00 and 11:00 a.m.before high temperatures inhibited ant activity. In tropical agroecosystems ants begin appearing on baits 5 min (personal observation). The presence of individuals of a particular species on a bait was taken as defining that position as within the foraging range of the species. Nests were located by following the recruitment trail at each bait back to the nest entrance. Very rarely would individual ants enter a hole that appeared to be more of an underground tunnel or foraging trail than the entrance to the nest. When this occured, further observations were made to locate the nest (i.e., searching for brood chambers). A variety of trials seeking to observe faunal turnover on individual baits convinced me that only rarely (I presume on borders of foraging ranges) was there any change in species occupation of a particular bait.

\section{Competition release experiment}

Six $6 \times 6 \mathrm{~m}^{2}$ plots were located within an adjacent coffee field where $S$. geminata and $P$. radoszkowskii were known to be the dominant ground foragers (Fig. 1). In three of the plots all colonies of $P$. radoszkowskii were killed with the application of a powdered organophosphate insecticide (Volaton) applied directly on the nest entrance. In the remaining three plots, colonies of $S$. geminata were killed using the same method. Due to the large size of $S$. geminata colonies and the behavior of building underground foraging trails that radiated from the center of the nests, the three plots were located according to the presence of a well established

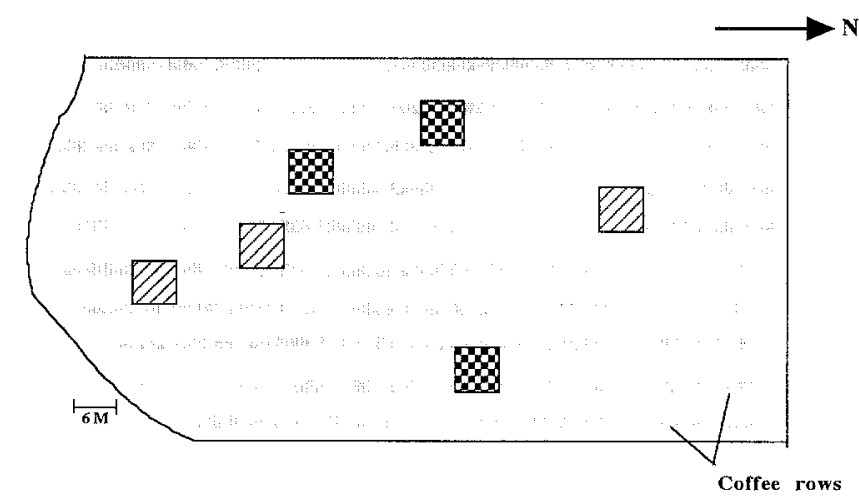

Fig. 1 Diagram of coffee field (at CICAFE) where competition release experiments were conducted. (Diagonal lines the Solenopsis geminata exclusion treatment, checkerboards Pheidole radoszkowskii exclusion treatment, gray bands coffee rows) 
colony, in such a way that the colony was located in the center of the plot. The insecticide was applied to the central $S$. geminata nest, and in addition, insecticide was also applied to fish baits that were occupied with $S$. geminata, so as to increase the effectiveness of the treatment (with rare exception a given bait was occuppied with only a single species).

In order to establish the foraging pattern of the two species before the elimination of the colonies, tuna fish baits (about $1 \times 1 \times$ $0.5 \mathrm{~cm}^{3}$ ) were placed on the ground forming a grid of seven columns and seven rows $1 \mathrm{~m}$ apart to give a total of 49 baits in each plot. Baits were checked after $20 \mathrm{~min}$ and the species present on the baits were recorded. All ant baiting was conducted during morning hours. To quantify abundance at baits a relative index of activity was used, where " 1 " represented 1-4 individuals, " 2 " represented 5-10 individuals and " 3 " represented 11 or more individuals. Baiting was repeated $24 \mathrm{~h}$ after the application of insecticide to check the effectiveness of the treatment, to locate nests that were overlooked during the first baiting and eliminate them, and to determine the extent to which non-target species were affected. Baiting was repeated 3 days after the first application of insecticide and results taken as the baseline. Baiting was repeated every 2 days thereafter for the next 2 weeks, and a final baiting was conducted 8 months later. The summation of the activity index for each species for each plot was used as an estimator of the species foraging activity. While a direct measure of abundance was not taken, foraging activity seems to reflect abundance patterns (Sacks and Carroll 1980).

\section{Foraging Behavior}

In a third coffee field dominated by these two species, an experiment was performed to estimate the time to encounter a resource and rate of accumulation of individuals within well-defined foraging areas for $S$. geminata and $P$. radoszkowskii. As explained below, both of these species forage in areas that are exclusively their domain for some period of time. A row of ten tuna fish baits (about $1 \times 1 \times 0.5 \mathrm{~cm}^{3}$ ) $5 \mathrm{~cm}$ apart from each other were simultaneously placed on the ground, within these well-defined foraging

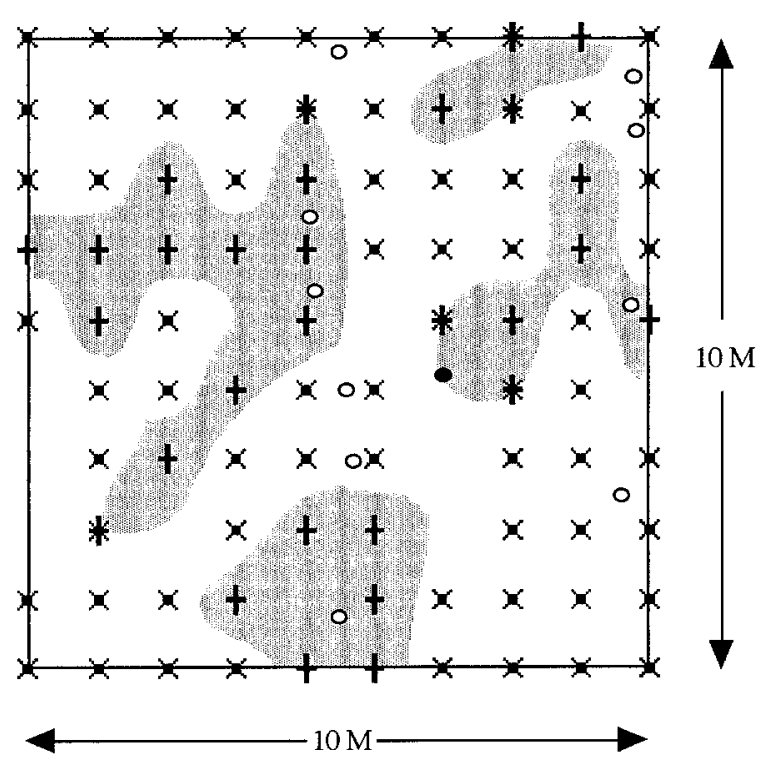

Fig. 2 Map of the experimental field where the foraging experiments were conducted showing the positions of the baits in a $1 \times 1$ $\mathrm{m}$ grid pattern. $(x$ positions occupied by Pheidole radoszkowskii, + positions occupied by Solenopsis geminata; $\theta$ position of the trials). Four trials were performed within the $S$. geminata foraging territory, six were performed within the $P$. radoszkowskii territory, and one (solid circle) was performed at a border between two territories areas, and checked every $15 \mathrm{~s}$ (plus $15 \mathrm{~s}$ to examine the 10 baits). At each check the number of individuals at each bait was recorded. From previous work (Perfecto 1990 1991a 1991b) it is evident that more than ten individuals are sufficient to completely dominate this bait, and thus when more than ten individuals were counted on a bait, it was recorded as 11 and no more ants were counted (so that 11 actually means "11 or more"). At the end of each trial, the nests of ants that arrived at the baits were located and the distance from the bait to the nest measured. Four trials were repeated within foraging territories of $S$. geminata and six within foraging territories of $P$. radoszkowskii (Fig. 2). The trials were conducted over a 2 -week period and included different colonies on every occasion. This methodology gives the average time it takes an individual ant to encounter a resource (within $30 \mathrm{~s}$ ), as well as the rate of recruitment of ants to a resource (rate of increase of net number of ants on a bait).

To examine the dynamics of this system at a border of foraging ranges, a row of ten baits, $5 \mathrm{~cm}$ apart, were set out so that they crossed previously determined foraging ranges of $S$. geminata and $P$. radoszkowskii (Fig. 2). The positioning of the baits was such that approximately half of them were in the $S$. geminata foraging territory and half were in the $P$. radoszkowskii foraging territory. Baits were checked at $15 \mathrm{~s}$ intervals, recording species and number on each of the ten baits.

\section{Results}

\section{Distribution and foraging ranges of the two species}

Figure 3 shows the foraging and nesting areas for $S$. geminata and $P$. radoszkowskii. The percentage of baits occupied by these two species varies significantly, with $P$. radoszkowskii occupying an average of $58 \%( \pm 6 \mathrm{SE})$ of the baits, and S. geminata occupying $22 \%( \pm 5, \mathrm{SE})$. Similarly, nest density varied from $0.22 \pm 0.006$ nests $\mathrm{m}^{-2}$ for $P$. radoszkowskii to $0.03 \pm 0.01$ nests $\mathrm{m}^{-2}$ for $S$. geminata. Despite these differences, it is apparent that these two species are coexisting and that they are co-dominant species in coffee fields [four other species (Dorymyrmex sp., Pheidole fallax, Brachymyrmex musculus, and Linepithema humile) shared the remaining baits with less than $6 \%$ occupancy].

\section{Competition release experiments}

Before treatments were established (i.e., before nests were poisoned) the activity index for each species was as expected (note the values for time $=0$, where time $=$ days after treatments in Fig. 4a, b). Since $P$. radoszkowskii was the dominant forager in areas in which it was to be eliminated, its activity index was larger than that of $S$. geminata. Since $S$. geminata was the dominant forager in areas in which it was to be eliminated, its activity index was larger than that of $P$. radoszkowskii. These relative values of foraging indices are quite constant, as established from previous studies both at this and other sites. While the absolute value of the index varies daily, the relative values of the two species remains relatively constant in a given plot, i.e., if one species dominates a particular site today, it has almost certainly been dominating that site for at least the past few months. 
Fig. 3 Map of three plots in the first experimental site indicating the foraging territories of Solenopsis geminata (shaded area). Also indicated are the positions of the baits occupied by: S. geminata $(X)$; Pheidole radoszkowskii $(+)$; and other species (ם). Circled symbols indicate the position of the nest for each species
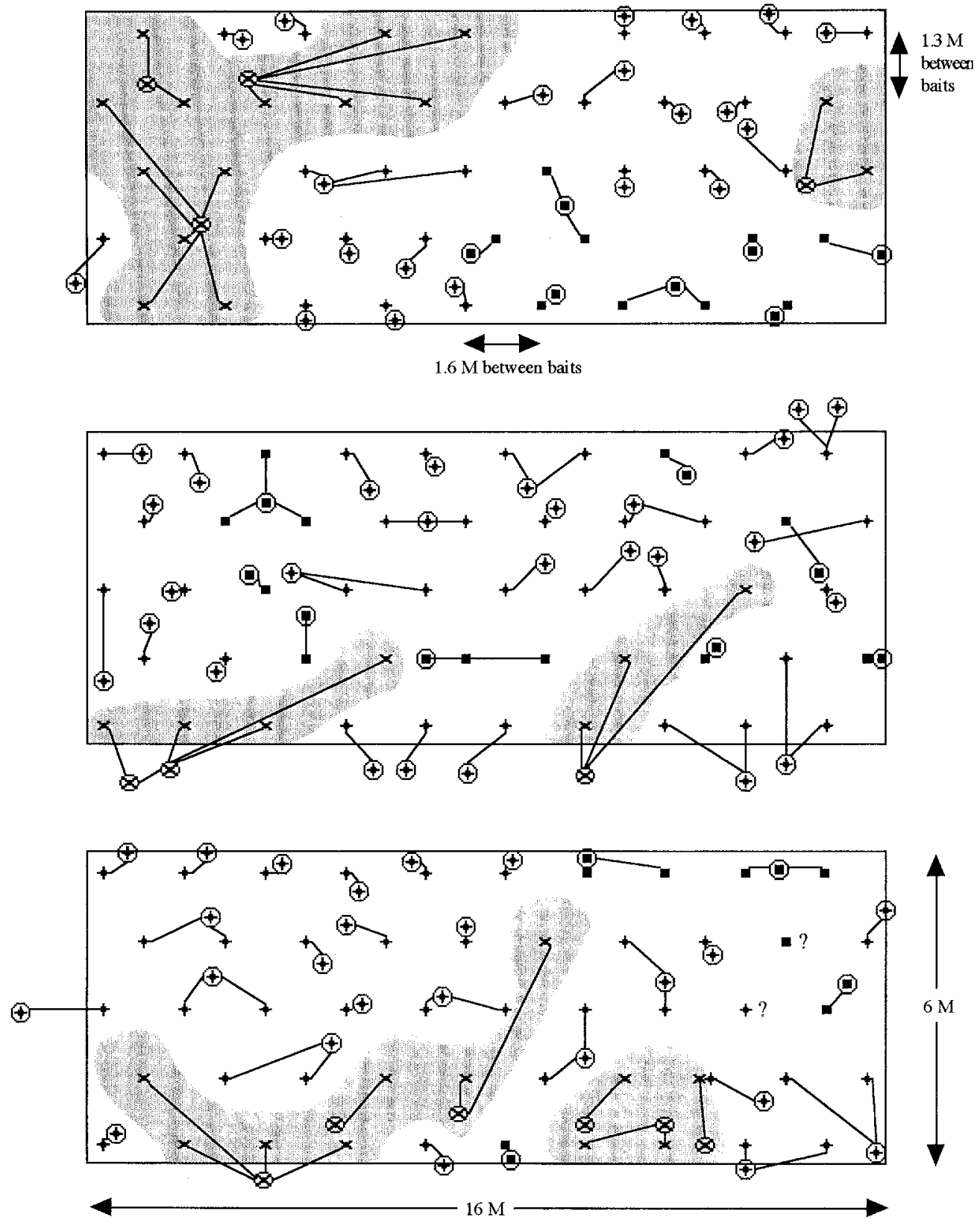

There was an unavoidable spill-over effect of the insecticide treatment, as clearly seen in the $S$. geminata exclusion treatment, where $P$. radoszkowskii activity declined after the treatment. Such an effect was also evident from field observations for the $P$. radoszkowskii exclusion treatment (i.e. one could visually detect fewer numbers of $S$. geminata foraging in the treatment areas), although it does not show up in the data (Fig. 4a). Such an effect is unavoidable but I believe it has no influence on the conclusions of the experiment. Some colonies, or portions of colonies, of the non-target species were affected, but the effect was minor compared to the effect on the target (in the case of $S$. geminata exclusion there was a reduction in activity index from about 65 to almost 0 for the target species and a reduction from about 40 to 20 for the non target species; in the case of P. radosz- kowskii the reduction of the target was from about 50 to less than 10 and the non-target was not reduced at all). It is thus difficult to see how this spillover effect could invalidate the qualitative conclusions about competition. Indeed, if there had been no spillover effect, the observed differences in foraging activity for days $2-10$ are likely to have been even larger than shown in Fig. 4a and $b$.

Following their exclusion, the activities of $P$. radoszkowskii and $S$. geminata declined dramatically, as expected. Thus, the relative dominance of the two species was reversed by the poisoning treatment. Through day 10 of the experiment, the activity reversal of both treatments remained in effect. Between days 10 and 20 the $P$. radoszkowskii exclusion treatments continued to show the same dominance pattern (Fig. 4a), but the S. gemina- 
a.
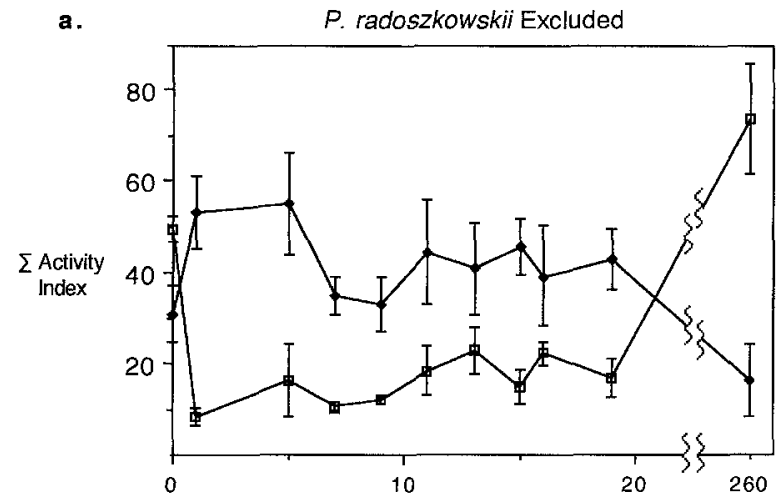

b.

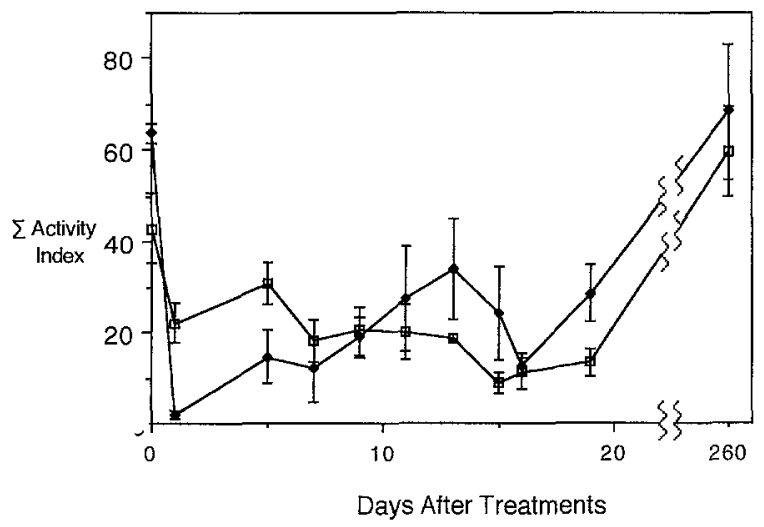

Fig. 4a Foraging activity of Solenopsis geminata $(-)$ and Pheidole radoszkowskii ( $\square$ ) before and after the elimination of $P$ Peidole radoszkowskii colonies. (Bars \pm SE for each date). b Foraging activity of Solenopsis geminata (-) and Pheidole radoszkowskii $(\square)$ before and after the elimination of Solenopsis geminata colonies. (Bars $\pm \mathrm{SE}$ for each date)

ta exclusion treatments reversed the pattern (Fig. 4b). This is precisely what was expected from the hypothesis of competitive dominance of $P$. radoszkowskii. Solenopsis geminata was able to quickly invade the foraging areas of $P$. radoszkowskii when the latter was removed, since the latter had been competitively restricting the former from those areas. It should also be noted that a detailed examination of the exact physical location of the foraging within each of the three plots confirmed that $S$. geminata in fact was foraging in areas in which $P$. $r a$ doszkowskii had been dominant before the treatment. Conversely, when $S$. geminata was removed, P. radoszkowskii did not have the ability to take over the areas formerly occupied by the former, since the absence of the latter was not in this case due to having been competitively restricted by the former. In contrast to the other treatment, a detailed examination of the exact physical location of the foraging within each of these three plots confirmed that $P$. radoszkowskii was not foraging in areas in which $S$. geminata had been dominant before the treatment. These data thus conform to the interpretation that $S$. geminata will occupy areas formerly occupied by the strong competitor $P$. radoszkowskii, but eliminating $S$. geminata from an area will not result in that area being occupied by $P$. radoszkowskii since its original absence from the area was not due to competition from $S$. geminata.

The experimental site was re-sampled 260 days after treatment initiation, and in both cases, the order of species dominance had reverted to its pre-treatment state. Note that the last sampling date was in a different season from the first, probably accounting for the difference in absolute values of the activity indices. As far as this experiment is concerned, the only important point is that the relative values of the activity indices returned to their original state (i.e., the species that dominated an area prior to the experimental intervention had returned to dominate that area 280 days later).

The differences shown graphically in Fig $4 \mathrm{a}$, b were statistically significant. Paired t tests were performed at each sampling date (activity index of one species versus the activity index of the other species in three plots for each experimental treatment), showing significant differences $(d f=2, P<0.05)$ for all dates save days 9 and 16 for the $S$. geminata removal treatment. Repeated measures ANOVA was not used because expected there would be a switch in dominance in the $S$. geminata removal treatment (an expectation clearly realized from a cursory examination of the data).

These results support the hypothesis that $S$. geminata activity is maintained at low levels because of the competitive effect of $P$. radoszkowskil, but not the reverse. Elimination of $S$. geminata colonies did not result in the same response from $P$. radoszkowskii, suggesting that this species' abundance is limited by factors other than competition from $S$. geminata. Where $S$. geminata was eliminated the initial decrease in its foraging activity gave way to a relatively rapid increase (after day 10 in Fig. 4b) as expected. This species is known to colonized disturbed areas (Perfecto 1991b). The recolonization in this case, in all three plots, came from colonies located outside the experimental plots. Pheidole radoszkowskii never took advantage of the initial elimination of $S$. geminata, suggesting that it is limited by other factors and not by competition from $S$. geminata.

\section{Foraging behavior}

The pattern of occupation of individual baits placed within well-defined foraging territories was highly variable for $S$. geminata (Fig. 5a) and relatively consistent for P. radoszkowskii (Fig. 5b). Such variability arises from the positioning of the baits at greater or lesser distances from a foraging trail or nest. In the four trials with $S$. ge minata, the time necessary to find all ten baits ranged from 16 min to $150 \mathrm{~min}$, whereas in the six trials with $P$. radoszkowskiithe time ranged from $5 \mathrm{~min}$ to $20 \mathrm{~min}$. The mean time necessary for $S$. geminatato find all ten baits was $53 \mathrm{~min}$, while $P$. radoszkowskii found them all within $10 \mathrm{~min}$, differences that are highly significant statisti- 
Fig. 5a,b Total number of ants on ten contiguous baits (separated from one another by 5 $\mathrm{cm}$ ) through time for a Solenopsis geminata, and $\mathbf{b} P$ Pheidole radoszkowskii

a.

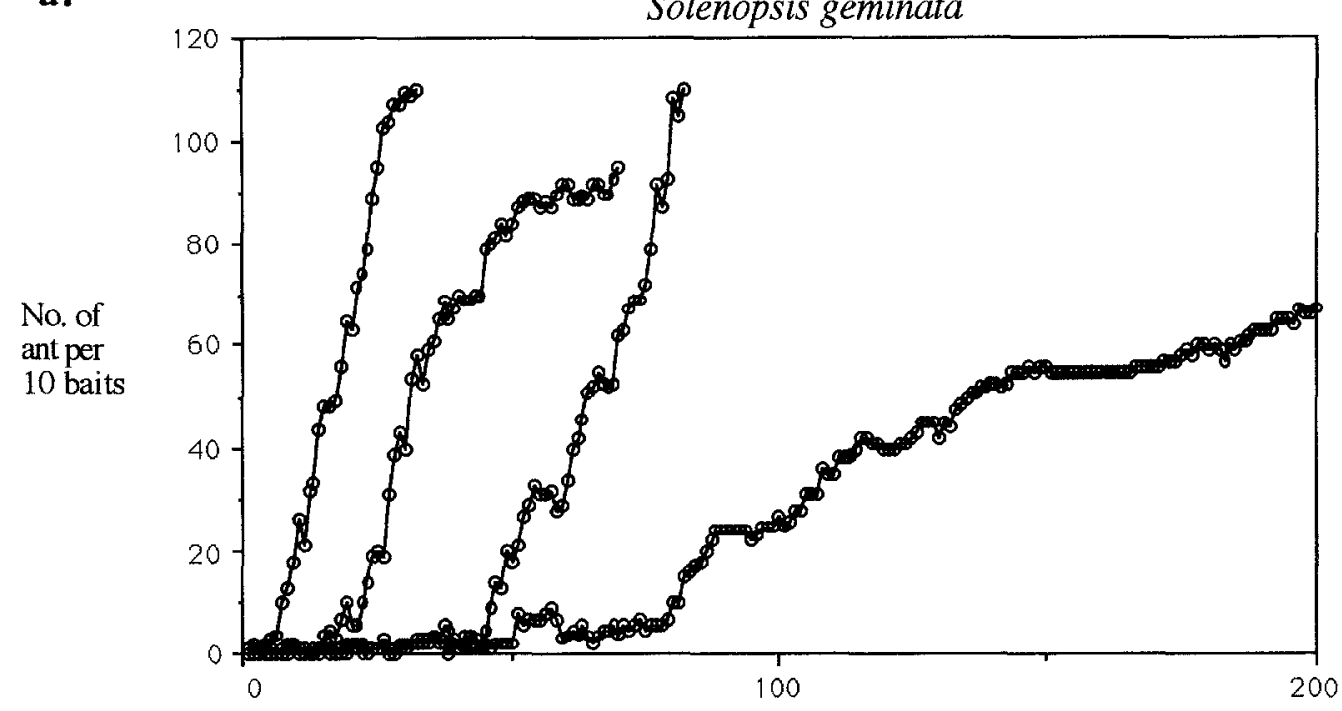

b.

Pheidole radoszkowskii

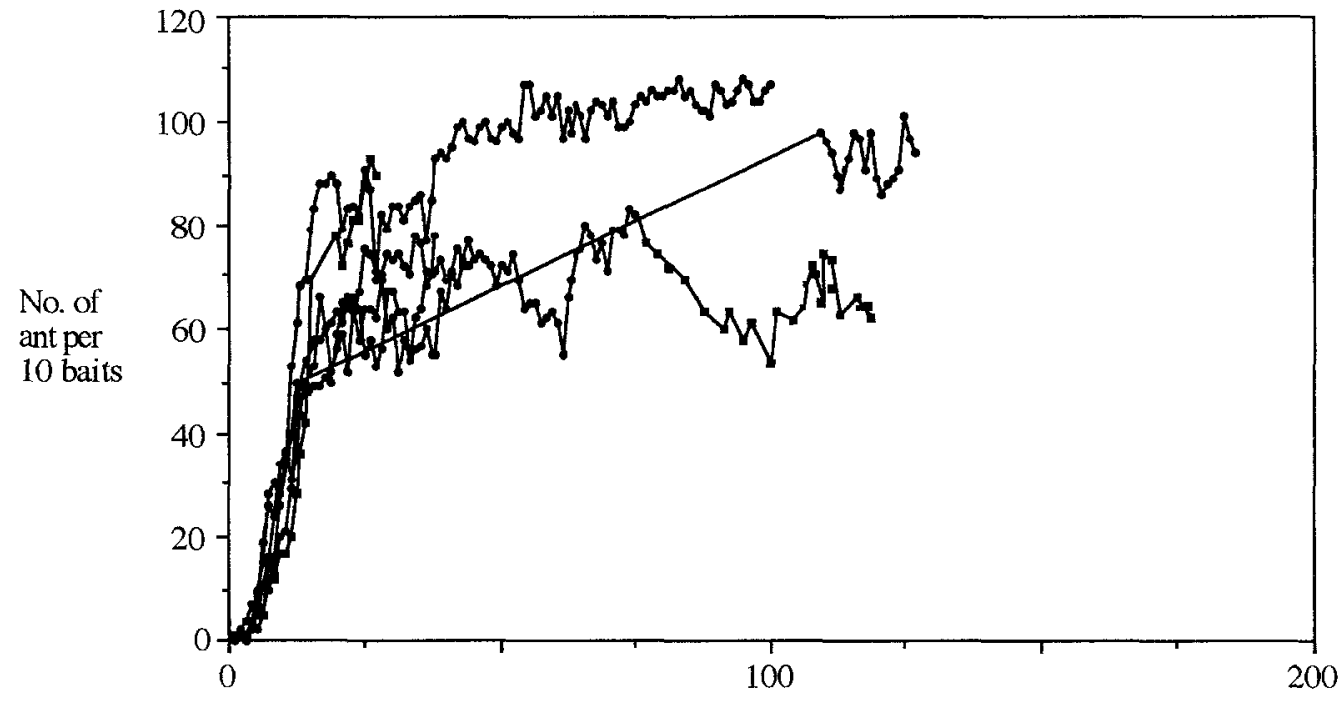

Time (minutes)

cally (after $\log$ transformation, $t=5.60, d f=370, P<$ 0.001 ).

The time necessary for $S$. geminatato discover a resource appears to depend on where it is located with regard to the foraging trails connected to the nest. In the $S$. geminata trials, the faster encounter $(14 \mathrm{~min}$.) was with resources positioned $22 \mathrm{~cm}$ from the nearest foraging trail were encountered faster $(14 \mathrm{~min})$, while the slowest encounter rate was with resources positioned $130 \mathrm{~cm}$ from the nearest foraging trail. For the other two intermediate encounter rates resources were positioned at 40 $\mathrm{cm}$ and $93 \mathrm{~cm}$ from the nearest foraging trail respectively. In contrast, $P$. radoszkowskii exhibited no relationship between rate of encounter and closeness to nest. The different rates of encounter can be explained by examining the structure and distribution of the nests of these two species. Pheidole radoszkowskii has small nests contain-

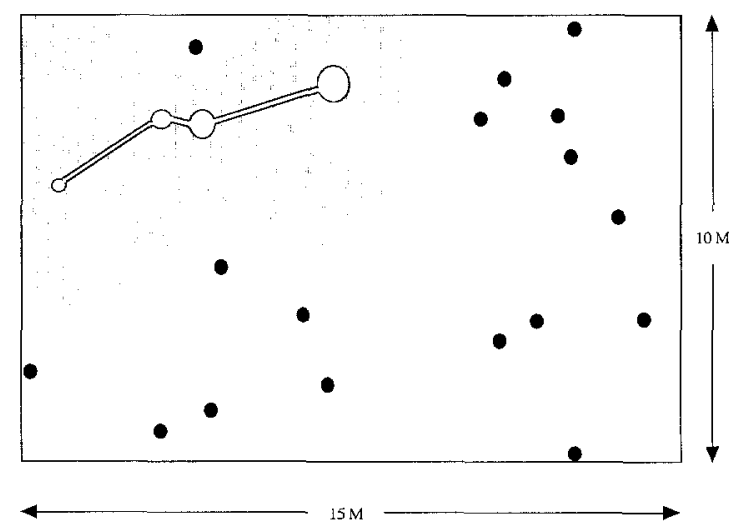

Fig. 6 Map of an experimental field showing the position of a foraging territory for a single Solenopsis geminata nest (shadow) and a well-defined foraging trail connected by exit/entrance holes, and the position of 17 scattered Pheidole radoszkowskii nests $(\lambda)$ 

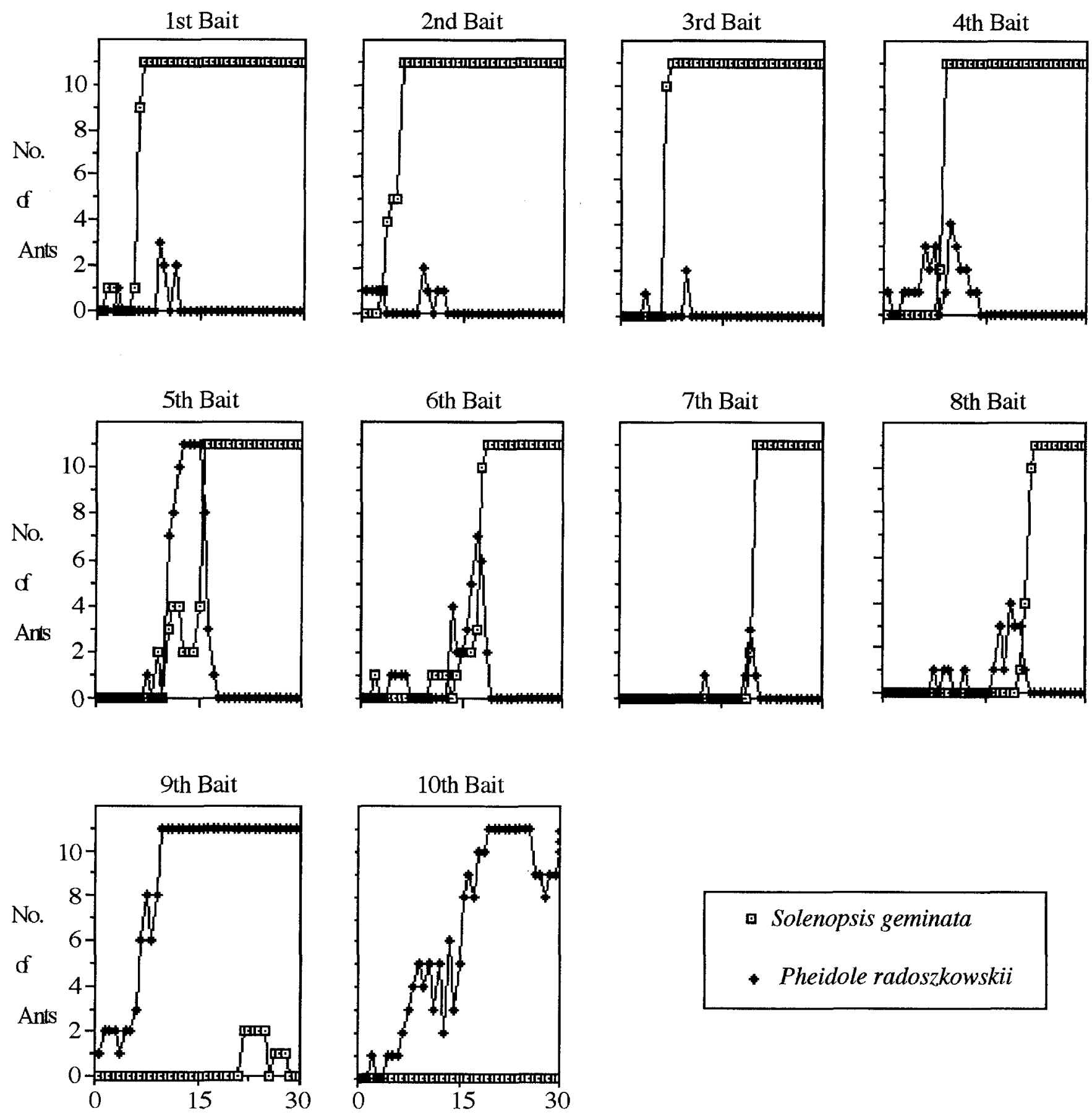

Fig. 7 Total number of ants through time in each one of ten contiguous baits $(5 \mathrm{~cm}$ apart) located at the border of Solenopsis geminata and Pheidole radoszkowskii territories

ing several hundred workers, while $S$. geminata usually has a large nest including a variety of covered, partially covered, and open foraging trails, with tens of thousands, and occasionally hundreds of thousands, of workers (Bhatkar 1988). Within the foraging range of $P$. radoszkowskii, a large number of seemingly independent colonies are to be found, scattered at random, while in the foraging range of $S$. geminata there might be only a sin- gle large colony. This pattern was well defined at all study sites, where $S$. geminatahad a few large colonies, while the rest of the area contained many much smaller $P$. radoszkowskii colonies (Figs. 3 and 6). A Student $t$ test showed a significant difference between the foraging distances (as estimated after each trial of the foraging experiment) from the nests of these two species $(t=2.835$, $d f=78, P<0.001$ ). The average distance travelled from nest to baits was $165.3 \mathrm{~cm}$ (maximum $470 \mathrm{~cm}$ ) for $S$. geminata and $102.8 \mathrm{~cm}$ (maximum $270 \mathrm{~cm}$ ) for $P$. radoszkowskii. The nature of the nests of these two species thus appears to account for the variable pattern in S. geminata and the relatively constant pattern in $P$. radoszkowskii. 
The trial performed on the border between $S$. gemina$t a$ and $P$. radoszkowskii foraging areas further confirms the above-mentioned results. Of the ten resources (baits) available, eight were eventually dominated by $S$. geminata, perhaps defining the actual border of its territory. However, of the ten resources, eight were first discovered by $P$. radoszkowskii, including six that lay on the supposed territory of $S$. geminata (Fig. 7).

\section{Discussion}

The foraging pattern and nest distribution of $S$. geminata and $P$. radoszkowskii suggest that these two species coexist and are co-dominant in the coffee agroecosystem. However, competition release experiments demonstrated that asymmetric competition is taking place, with $\mathrm{P}$. $\mathrm{ra}$ doszkowskii competing strongly against $S$. geminata, but not the reverse. Foraging experiments suggest that the mechanism for this asymmetry is the superior foraging efficiency of $P$. radoszkowskii. However, the study also suggests that if large resources dominate the resource spectrum, $S$. geminata could have a competitive advantage over other less aggressive species. Thus, for example, when underground root aphids are abundant, as is frequently the case when grasses invade an ecosystem, or when large fruits are frequently available on the ground, as in some tropical fruit orchards, $S$. geminata may be favored because of its unique ability to defend large resources. However, in situations in which resources occur in smaller packets, such that an individual ant of other species encounters and removes the resources before they are ever discovered by $S$. geminata, then $S$. geminata loses any advantage due to aggressiveness.

Part of S. geminata's ability to dominate under some circumstances could be due to its colony size and nest structure (Fig. 8), which is dramatically different from that of $P$. radoszkowskii(Fig. 9). An individual S. geminata nest can grow to be an enormous structure with a large number of subsurface foraging trunk trails. While much of the ants' actual foraging takes place above ground, ants frequently move to foraging areas through these subsurface trunk trails (personal observation). The nest of $P$. radoszkowskii is small. Two dissected nests contained $\pm 1,200$ and $\pm 1,350$ workers respectively, compared to the hundreds of thousands of workers reported for $S$. geminata (Bhatkar 1988). The majority of $P$. radoszkowskii's foraging is epigaeic, and its rate of encountering resources within its own foraging area is much larger than that of $S$. geminata.

The observations presented here may have practical consequences, depending on how $S$. geminata is viewed. Several studies have reported this species as a potential biological control agent of insect pests (weeds and insects) in agroecosystems (Risch 1981; Torres 1982; Risch and Carroll 1982a, b; Perfecto 1991a; Perfecto and Sediles 1992). This study suggests that a way to increase the abundance of $S$. geminatawill be to control other ant species. On the other hand the species is clearly a poten-

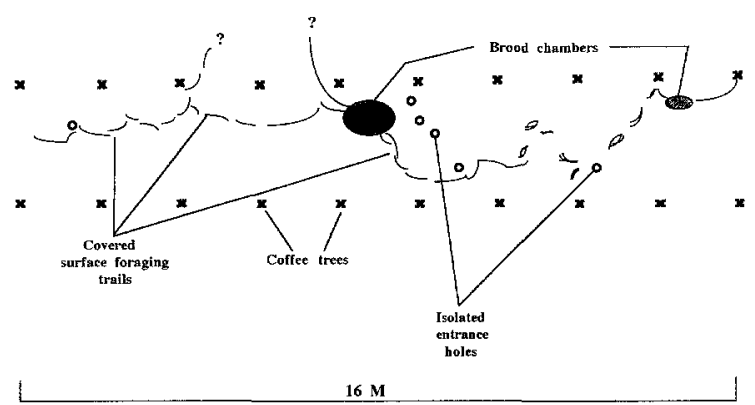

Fig. 8 Diagram of the horizontal extension of a Solenopsis geminata nest indicating locations of brood chambers and soil-covered surface trail

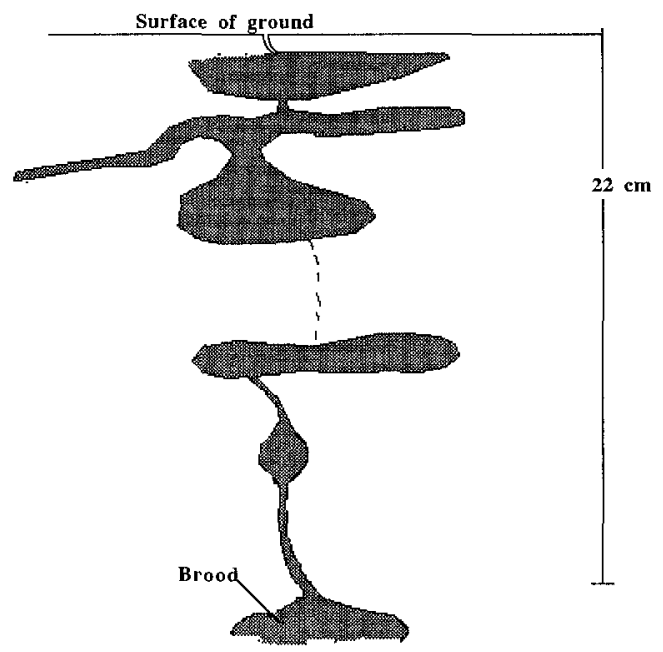

Fig. 9 Diagram of the vertical extension of a Pheidole radoszkowskii nest indicating position of the brood chamber

tial agricultural pest under some conditions (I have seen it tending large numbers of coccinellds on coffee, and aphids on the flower stalks of cacao plants). Fire ants have also been reported to eat certain crop seeds and interfere with crop yields (Logfren et al. 1975; Kidd and Apperson 1984). During the planting of tomatoes in the Sébaco Valley of Nicaragua in 1989, the species destroyed over $90 \%$ of the planted seeds (A. Sediles, personal communication), and in southern Mexico it routinely destroys planted corn seed (J.H. Vandermeer, personal communication). If $S$. geminatareaches pest status, the most common response of a producer is to apply an insecticide. But such application may be exactly the wrong strategy if part of the natural control of S. geminata is related to competition with other ants in the system. Insecticide application could be just what the species needs to extend its domination over the area in question. An alternative strategy may be to promote nesting sites for other species of ants.

Because of its ability to dominate resources that come in large patches, there are some ecosystems in which $S$. geminata can be expected to dominate, even though no recent disturbance is evident. Abandoned fruit orchards in which resources are in the form of ripe and rotting fruits, beaches where marine organic matter in the form 
of dead fish and other animals is routinely washed ashore, and grassy lawns in which grass species suitable for root homopterans exist, are all likely ecosystems. I have routinely observed the species in all such ecosystem types. But, if the mechanisms reported herein are applicable to these other ecosystems, its presence is due, at least partially, to a suite of behavioral characteristics combined with habitat disturbance that result in competition release, and not simply because of its aggressiveness.

In sum, through the removal experiment we see that there is an asymmetry in the competitive relationship between Pheidole radoszkowskii and Solenopsis geminata. Pheidole radoszkowskii is the competitively dominant species and seems to be able to eliminate $S$. geminata when the habitat is suitable. The mechanism of this competitive dominance appears to be the superior foraging efficiency of $P$. radoszkowskii compared to that of $S$. geminata. On the other hand, $S$. geminata is able to dominate resources once they are encountered, recruiting large numbers of workers through their underground foraging trails. The overall pattern thus seems to be that $S$. geminata will dominate an area either because it is unsuitable to $P$. radoszkowskii or because the predominant form of available resources comes in large packages, while areas suitable for $P$. radoszkowskii and in which available resources come in small patches, will come to be dominated by $P$. radoszkowskii.

Acknowledgements This work was supported by University of Michigan Office of Vice Provost for Research and the National Science Foundation Grant \# RII-9012484. I thank Dave Andow, Cathy Bach, Brian Hazlett, Dick Levins, David Pimentel, Beverly Rathcke, John Vandermeer and Earl Werner for helpful comments on the manuscript, David Cappaert and Susanna Remold for assisting in data collection, and Roy Snelling for identifying the ant species.

\section{References}

Benítez J, Perfecto I (1990). Efecto de diferentes tipos de manejo de café sobre las comunidades de hormigas. Agroecol Neotropic 1: 11-15

Bhatkar AP (1988). Confrontation behavior between Solenopsis invicta, S. geminata, and other Florida ant species. In: Trager JC (ed) Advances in myrmecology. E. J. Brill, Leiden, pp 445-464

Brown JH, Reichman OJ, Davidson DW (1979). Granivory in desert ecosystems. Annu Rev of Ecol Syst. 10: 201-227

Carroll, CR, Jansen DH, (1973) Ecology of foraging by ants. Annu Rev Ecol Syst 4: 231-257

Carroll, CR, Risch SJ (1984) The dynamics of seed harvesting in early successional communities by a tropical ant, Solenopsis geminata. Oecologia 61: 388-392

Hansen SR (1978) Resource utilization and coexistence of three species of Pogonomyrmex ants in an Upper Sonora grassland community. Oecologia 35: 109-117
Hölldobler B (1981) Foraging and spatiotemporal territories in the honey ant Myrmecocystus mimicus Wheeler (Hymenoptera: Formicidae). Behav Ecol Sociobiol 9: 301-314

Kidd KA, Apperson CS (1984) Environmental factors affecting relative distribution of foraging red imported fire ants in a soybean field on soy and plants. Agric Entomol 1: 212-218

Levings SC, (1983) Seasonal, annual, and among-site variation in the ground ant community of a deciduous tropical forest: some causes of patchy species distributions. Ecol Monogr 53: $435-455$

Levins RL, Pressick M, Heatwole H (1973) Coexistence patterns in insular ants. Am Sci 61: 463-472

Logfren CS, Banks WA, Glancey BN (1975) Biology and control of imported fire ants. Annu Rev Entomol 20: 1-29

Nestel D, Dickschen F (1990) The foraging kinetics of ground ant communities in different coffee agroecosystems. Oecologia 84: $58-63$

Perfecto I, (1990) Indirect and direct effects in a tropical agroecosystem: the maize-pest-ant system in Nicaragua. Ecology 71 : 2125-2134

Perfecto I, (1991a) Ants (Hymenoptera: Formicidae) as natural control agents of pests in irrigated maize in Nicaragua. $J$ Econ Entomol 84: 65-70

Perfecto I, (1991b) Dynamics of Solenopsis geminata in a tropical fallow field after ploughing. Oikos 62: 139-144

Perfecto I, and A. Sediles. 1992. Vegatational diversity, ants (Hymenoptera: Formicidae), and herbivorous pests in a neotropical agroecosystem. Environ Entomol 21: 61-67

Perfecto I, Vandermeer JH, (in press) Understanding biodiversity loss in agroecosystems: reduction of ant diversity resulting from transformation of the coffee ecosystem in Costa Rica. Trends Agric Sci Entomol

Risch SJ, (1981) Ants as important rootworm eggs in the neotropics. Journal of Econ Entomol 74: 88-90

Risch SJ, Carroll CR (1982a) The ecological role of ants in two Mexican agroecosystems. Oecologia 55: 114-119

Risch SJ, Carroll CR (1982b) Effect of a keystone predaceous ant Solenopsis geminata, in a non-equilibrium community. Ecology 63: 1979-1983

Saks ME, Carroll CR (1980) Ant foraging in tropical agroecosystems. Agro-Ecosystems 6: 177-188

Schoener TW (1986) Patterns in terrestrial vertebrate versus arthropod communities: do systematic differences in regularity exist? In: Diamond J, Case TJ (eds) Community ecology. Harper and Row, New York, pp 556-586.

Sediles A (1990). Impacto de Lorsban on la presencia de la hormiga Solenopsis geminata en un sistema de maíz (Zea mays). Agroecol Neotropic 1: 35-36

Sovalainen R, Vepsäläinen K (1989) Niche differentiation of ant species within territories of the wood ant Formica polyctena. Oikos 56: $3-16$

Swain RB (1977) The natural history of Monacis, a genus of Neotropical ants (Hymenoptera: Formicidae). Ph.D. dissertation, Harvard University

Torres JA, (1982) Biological control and the possible use of ants in biological control of insects. Science-Ciencia 9: 39-44

Vepsäläinen K, Pisarski B (1982) Assembly of island ant communities. Ann Zool Fenn 19: 327-335

Way MJ (1963) Mutualism between ants and honeydew-producing Homoptera. Annu Rev Entomol 8: 307-344

Wilson EO (1978) Division of labor in fire ants based on physical caste (Hymenoptera: Formicidae: Solenopsis). J Kansas Entomol Soc 51: 615-636 